\title{
Color Sorting Robot
}

\author{
Snehal Shirgave $^{1}$, Aishwrya Salunkhe ${ }^{2}$, Khadija Shirgave ${ }^{3}$, S. Y. Upadhye ${ }^{4}$ \\ Student, Department of Electronics, DKTE's Textile and Engineering Institute, Ichalkaranji, Maharashtra ${ }^{1,2,3}$ \\ Professor, Department of Electronics, DKTE's Textile and Engineering Institute, Ichalkaranji, Maharashtra ${ }^{4}$
}

\begin{abstract}
In industry there is highly increasing demands for automation. Sorting of objects based on color is very difficult task. This paper gives us an idea about color sorting project. Here we are designing and implementing an efficient color sorting robot using color sensor TCS3200 based on Arduino UNO. This project provides high accuracy and performance. Easy to operate and construct which reduces human errors.
\end{abstract}

Keywords: Arduino UNO controller, TCS3200 color sensor, servo motors.

\section{INTRODUCTION}

Now a days industry wants high accuracy and performance in their products. Color is one of the best parameter on which we can sort different objects at industry level. Paper gives us an idea about how the color sorting robot works and reduces human efforts. These color sorters can be used in agriculture field to sort grains, rice, fruits etc. These also can be used in different industrial applications like in plastic industries to sort toys, to sort various colored nuts and bolts. This Robot is constructed using plywood of $3 \mathrm{~mm}$ thickness.

\section{LITERATURE SURVEY}

The compilation of system and interfacing of different components, sensors, servo motors, Hardware and software interfacing of the system is prescribed by the "Software Interfacing of TCS3200 color sensor with arduino"

"LIM JIE SHEN [1] in this paper a color sorting robot is researched designed and created with Arduino UNO microcontroller, TCS3200 color sensor, SG90 tower pro servo motor and other electronics component. They found that color sensor gives different results when it tested outdoor and indoor.

Dhanoj M.[4] was researched on robotic arm based color sorting robot using this TCS3200 color sensor. They were also used LCD display to display the color detected. In image processing image is captured using real time system like webcam and then objects can be sorted as per our requirement like on the basis of shapes and colors[5].

Li Quaoyi [6] has used one method to test sensor's output. They took an one empty tube and at the bottom of that tube they placed sensor and white light is placed at the top of the tube so that they went to know the filters are gated successively to measure the red, green and blue values and calculated other parameters. An article written by Bishop and Lee human eye can give response only to the lights which are in the range of visible light spectrum[8].

\section{SYSTEM BLOCK DIAGRAM}

As shown in fig1. system consists of color sensor module, servo motors, arduino UNO and lcd display. TCS3200 is the color sensor which detects light reflected by an object and converts it into frequency. Servo motors are used to move a slider according to the color detected. Input and output operations are controlled by an arduino UNO microcontroller. Detected output color and the count value of respective colored object is displayed on lcd.

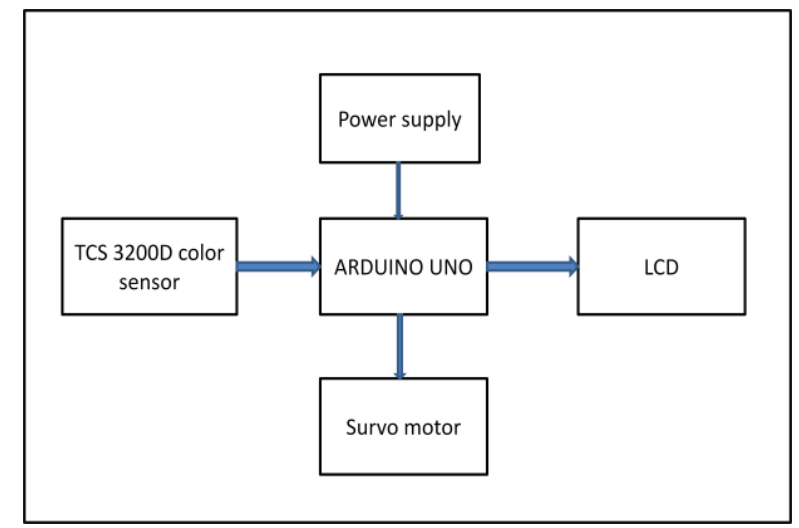

Fig1.

\section{COLOR DETECTION}

TCS3200 is the color sensor which converts light intensity into frequency. It has an array of 64 photodiodes divided into 4 types namely red, green, blue and no color each of using $(4 * 4) 16$ photodiodes. Selection of photodiodes is made up with the help of pins S2 and S3 [2] as shown in fig2.

\begin{tabular}{|c|c|l|}
\hline S2 & S3 & PHOTODIODE TYPE \\
\hline L & L & Red \\
\hline L & H & Blue \\
\hline H & L & Clear (no filter) \\
\hline H & H & Green \\
\hline
\end{tabular}

Fig2. 
TCS3200 color sensor detects reflected light from an object which are in the range of visible light spectrum (fig3) and convert it into frequency with the help of inbuilt current to frequency converter (fig4) and gives us output in the form of frequencies of RGB components.

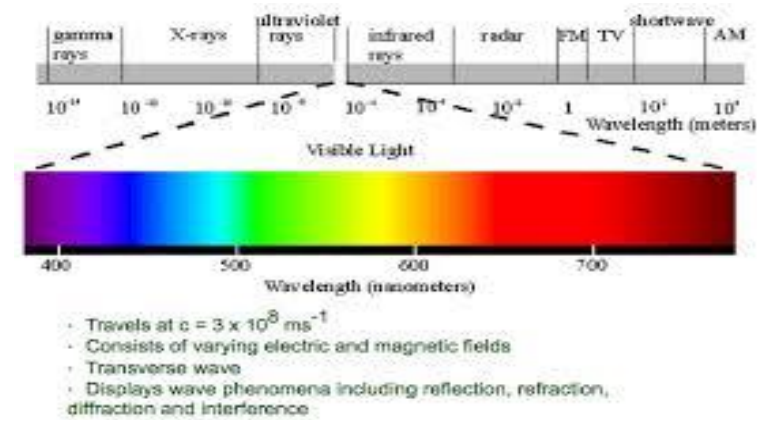

Fig3.

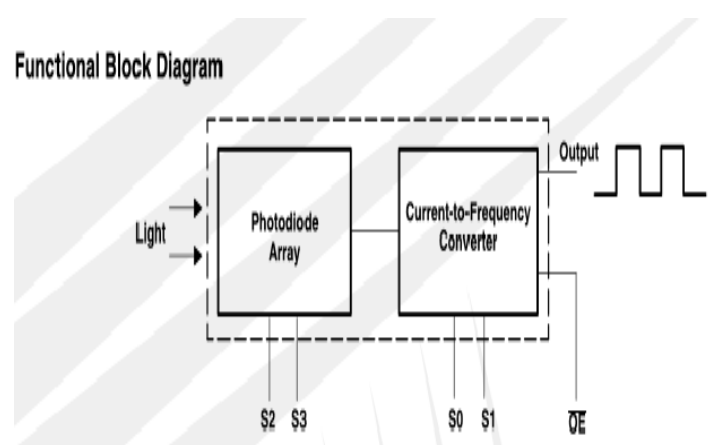

Fig4.

\section{SORTING OF OBJECT}

Servo motors have high torque as $1.8 \mathrm{Kglcm}$ and wide speed range. Here we are using two $\mathrm{Sg} 9$ micro servo motors to sort objects according to the color detected by sensor. It rotates approximately 180 degree 90 degree in each direction. Fig5 shows the pwm cycle to set the rotation.. Position "0" (1.5 ms pulse) is middle, "90" $(\sim 2 \mathrm{~ms}$ pulse) is middle, is all the way to the right, "-90" $(\sim 1 \mathrm{~ms}$ pulse $)$ is all the way to the left

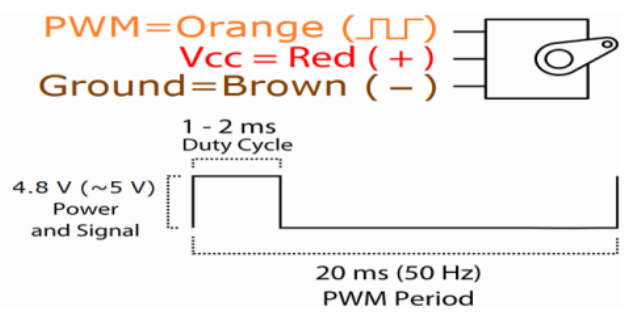

Fig5.

Fig6. shows the actual process of our project that how it is going to work. Top motor is used to collect the balls and place it on the platform for color detection procedure. Sensors detects the color of ball and gives output to the arduino so that it can rotate bottom motor which is used for sorting of balls according to the color detected.

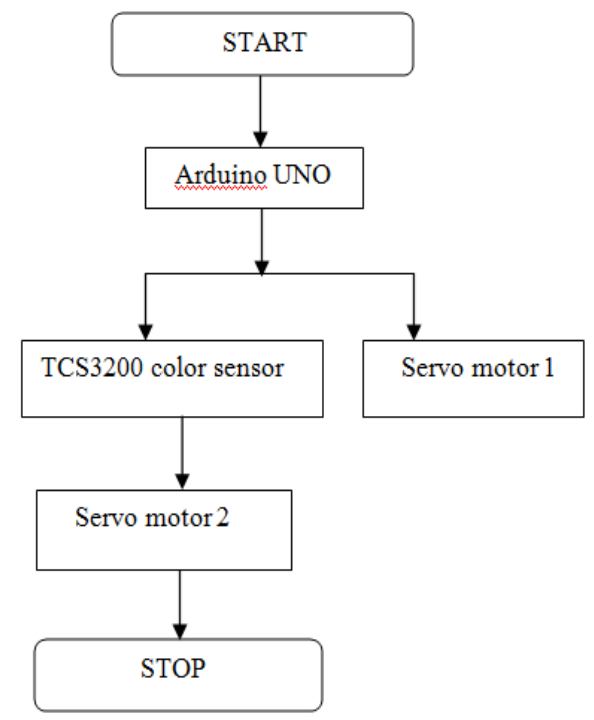

Fig6.

Direct interfacing of motors with a controller gives a little bit over load on whole system operation to overcome this drawback the motor driver circuit is used to provide high current to motor[4]. We are using L293D IC to built motor driver circuit. This driver circuit is supposed to take low level input signal from arduino uno and to provide required high voltage and current to motor for its accurate operation. Motor is used to drive the slider over the detected color station. Motor operation is fully controlled by an arduino. L293d is supposed to drive current up to $600 \mathrm{~mA}$ with voltage $4.5 \mathrm{~V}$.

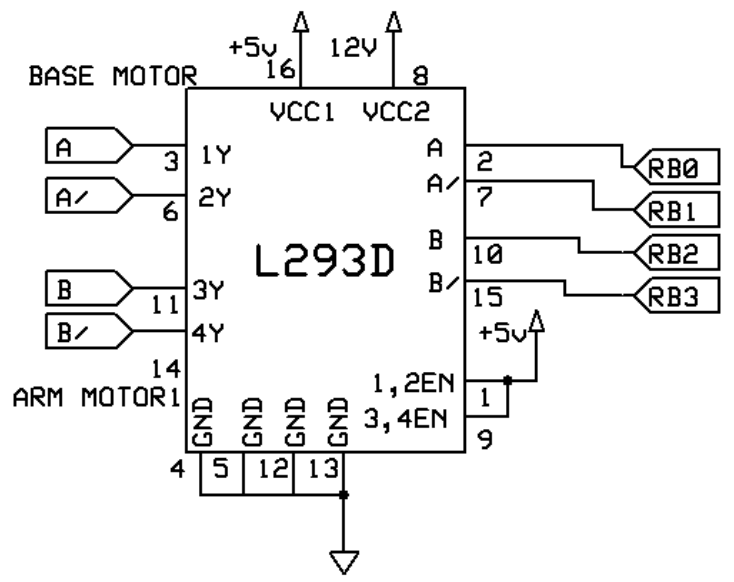

Fig7.

\section{COLOR AND COUNT DISPLAY}

To display the status of system output and respective count we are using 16*2 alphanumeric lcd display. Which also display the degree of rotation of bottom motor.

\section{RESULT}

Fig8 shows how the motors are going to work, how top motor collects a ball from a container and place it on the 
platform to detect color. After color detection process bottom motor will rotate according to color detected and put the balls in their respective boxes. Color of ball, degree of rotation of bottom motor and count values are displayed on LCD display.

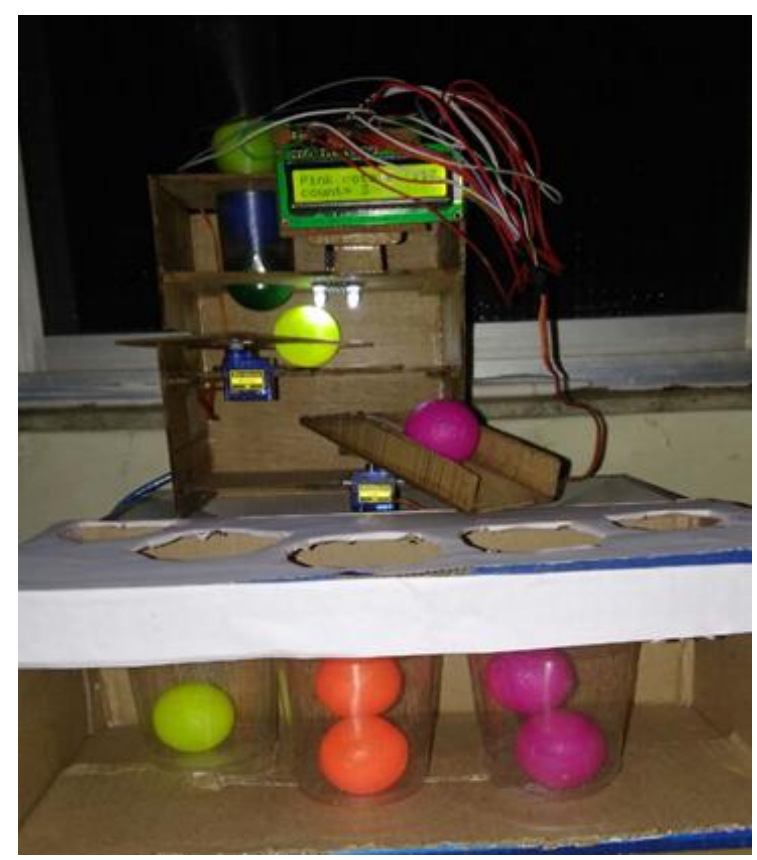

Fig8.

\section{CONCLUSION}

In this project the developing of a color sorting robot has been achieved. Color sensor TCS3200 gives precise output. It can be improved by using different advanced color sensors and microcontrollers. As per our requirement we can put limitation on objects to be sort and replace fully containers with the empty one using arm.

\section{REFERENCES}

[1] LIM JIE SHEN*, IRDA HASSAN "Design and Development of Color Sorting Robot " EURECA 2014 Special Issue January (2015).

[2] http://www.mouser.com/catalog/specsheets/TCS3200-E11.pdf

[3] Aji Joy "Object Sorting Robotic Arm Based on Color Sensing" International Journal of Advanced Research in Electrical, Electronics and Instrumentation Engineering Vol. 3, Issue 3, March 2014

[4] Dhanoj M, Reshma K V, Sheeba V, Marymol P "Color Sensor Based Object Sorting Robot Using Embedded System" International Journal of Advanced Research in Computer and Communication Engineering vol. 4, Issue 4, April 2015.

[5] Abhishek Kondhare, Garima Singh, Neha Hiralkar, M.S.Vanjale "Colour And Shape Based Object Sorting" International Journal Of Scientific Research And Education $\|$ Volume\|2\|Issue\| 3 ||Pages|553-562||2014|| ISSN (e): 2321-7545.

[6] Li qiaoyi "Study on Color Analyzer Based on the Multiplexing of TCS3200 Color Sensor and Microcontroller" ijhit Vol 7, no 5 (2014).

[7] Uzma Amin, Ghulam Ahmad, Nudrat Liaqat, Manzar Ahmed, Sumbal Zahoor "Detection \& Distinction of Colors using Color Sorting Robotic Arm in a Pick \& Place Mechanism" International Journal of Science and Research (IJSR) ISSN (Online): 2319-7064.
[8] Akriti Kaushik, Aastha Sharama "Rgb Color Sensing Technique" IJARSE, Vol. No.2, Issue No.9, September 2013.

[9] Kunhimohammed C. K, Muhammed Saifudeen K. K, Sahna S, Gokul M. S and Shaeez Usman Abdulla "Automatic Color Sorting Machine Using TCS230 Color Sensor And PIC Microcontroller" International Journal of Research and Innovations in Science and Technology .Volume $2:$ Issue $2: 2015$. 